\title{
CONSTRUCTION OF THE DEFINITION OF THE “CREDIT” CATEGORY
}

\author{
Elena G. Revtova \\ Orenburg State University, Orenburg, Russian Federation
}

\begin{abstract}
The subject of the research is the essence, nature and meaning of the "credit" category. The goal is to develop a definition of the "credit" category reflecting the nature of the phenomenon it refers to. Hypothesis: the author believes that general scientific research methods based on the idea of triadicity will reveal and describe the nature of the phenomenon of credit, as well as formulate a scientifically based definition of the corresponding category. Methods: formal-logical method, method of triadic decoding of categories. As a result of using the formallogical method the author defined: a) the generic concept "loan" as a universe, part of which is the "credit" category; b) non-credit forms of loans: "bill", "bond", "factoring", "leasing"; c) necessary and sufficient conditions for classifying an object as a "credit". A scientifically grounded definition of the "credit" category was formulated. As a result of deciphering the "credit" category, the essential qualities in the "credit" object, which together make up its essence, nature and meaning, were revealed; a detailed definition of the "credit" category was received. The research into the nature of credit has shown that the closest generic concept of credit is a loan; a necessary condition for classifying a credit as a loan is the transfer or receipt of money and goods on loan; repayment, payment and urgency are sufficient conditions for classifying a credit as a loan category; as a result, "credit" is defined as a kind of loan categories, the objective essential properties of which are repayment, payment and urgency. The field of applicability of the results in theory: the possibility of using the formal-logical method to investigate the nature of the research object; to check the obtained definition of the object for logical correctness; to enter your own definitions of the research object into the subject field with the help of "triads". In lending practice the results are applicable as follows: scientifically grounded definition of the "credit" category, understanding the essence and nature of credit, its properties: repayment, payment and urgency to determine the specific variety of credit.
\end{abstract}

Key words: credit, loan, category, urgency, payment, repayment, formal-logical method, method of triadic decoding of categories.

Citation. Revtova E.G. Construction of the Definition of the "Credit" Category. Vestnik Volgogradskogo gosudarstvennogo universiteta. Ekonomika [Journal of Volgograd State University. Economics], 2020, vol. 22, no. 4, pp. 122-131. (in Russian). DOI: https://doi.org/10.15688/ek.jvolsu.2020.4.11

УДК 336.27

ББК 65.262

Дата поступления статьи: 29.10.2020

Дата принятия статьи: 16.11.2020

\section{КОНСТРУИРОВАНИЕ ДЕФИНИЦИИ КАТЕГОРИИ «КРЕДИТ»}

\section{Елена Геннадьевна Ревтова}

Оренбургский государственный университет, г. Оренбург, Российская Федерация

\footnotetext{
Аннотация. Предмет исследования - сущность, суть, природа и смысл категории «кредит». Цель разработать дефиницию категории «кредит», отражающую природу именуемого ею феномена. Гипотеза: мы полагаем, что общенаучные методы исследования, основанные на идеи триадичности, позволят выявить и описать природу феномена кредита, а также сформулировать научно обоснованное определение соответствующей категории. Методы: формально-логический метод, метод триадической дешифровки категорий. В результате использования формально-логического метода получено научно обоснованное определение 洋 категории «кредит», а также определены: а) родовое понятие «займ» как универсум, частью которого является искомая категория «кредит»; б) некредитные формы займа: «вексель», «облигация», «факторинг», «лизинг»; в) необходимое и достаточные условия отнесения объекта к классу «кредит». В результате дешиф() ровки категории «кредит» выявлены существенные качества в объекте «кредит», составляющие в совокуп-
} 
ности его суть, природу и смысл; получено развернутое определение категории «кредит». Исследование природы кредита показало, что его ближайшим родовым понятием является займ; необходимым условием отнесения кредита к классу займов является передача или получение денег и товара взаймы; возвратность, платность и срочность являются достаточными условиями отнесения категории кредита к классу; в результате «кредит» определен как род категорий займа, объективными существенными свойствами которого являются возвратность, платность и срочность. Область применимости результатов: 1) в теории: возможность с помощью формально-логического метода исследовать природу объекта исследования; проверить полученное определение объекта на предмет логической корректности; с помощью «триад» ввести в предметное поле собственные определения объекта исследования; 2) в кредитной практике: научно обоснованное определение категории «кредит», понимание сущности и природы кредита, его свойств (возвратности, платности и срочности для определения видового разнообразия кредита).

Ключевые слова: кредит, займ, категория, срочность, платность, возвратность, формально-логический метод, метод триадической дешифровки категорий.

Цитирование. Ревтова Е. Г. Конструирование дефиниции категории «кредит» // Вестник Волгоградского государственного университета. Экономика. - 2020. - Т. 22, № 4. - С. 122-131. - DOI: https:// doi.org/10.15688/ek.jvolsu.2020.4.11

\section{Введение}

В научном мире, где не только недостаток, но и обилие сформулированных определений объекта исследования не упрощает, а затрудняет понимание категории, тормозит развитие научной теории, попытки обратиться к продуктивной методологии для получения системы базовых категорий и производных понятий предметной области являются весьма актуальными.

Конструирование дефиниций имеет большое значение для отражения сущности и природы исследуемого феномена, позволяет выделить его из ряда сходных, но не тождественных феноменов.

Научное направление, связанное с исследованием кредита, насчитывает в настоящее время большое число определений. Они отличаются выделенными принципами, формами, отношениями, условиями, структурными элементами. Многообразие определений и отсутствие полноты, согласованности и системности имеющихся научных представлений сути, сущности и природы кредита препятствуют развитию научной теории кредита, которая крайне необходима для решения актуальных социально-экономических задач.

В то же время исследователи, конструирующие и разрабатывающие дефиниции изучаемой экономической категории, сталкиваются с проблемой поиска и выбора надежного научного инструментария. Чаще всего для описания идентифицируемой категории в экономической науке исследователи используют традиционные приемы: фактологический и исторические подходы (методы), лингвистическое толкование категории, генетический анализ. В результате сложившиеся к настоящему времени определения кредита не позволяют точно идентифицировать его, что является препятствием для развития научной теории данного феномена.

Итак, мы полагаем, что общенаучные методы исследования, в частности базирующиеся на сочетании формальной логики и идеи триадичности, позволят выявить и описать природу феномена «кредит», а также сформулировать научно обоснованное определение соответствующей категории.

\section{Обзор разработанности проблемы в научной литературе}

В теоретическом отношении кредиту, известному всему миру не одно столетие, посвящали свои работы зарубежные и российские ученые и практики, объясняя его суть, сущность и природу. Рассматривая сущность кредита, ее смысл, исследователи приводят множество определений, одно из которых принадлежит О.И. Лаврушину. Он утверждает, что «сущность кредита - это его внутреннее устройство, она выступает как главное в содержании этой экономической категории» [Деньги, кредит, банки, 2010, с. 237]. Также, по мнению О.И. Лаврушина, конкретными характеристиками кредита, которые «показывают сущность в целом», являются: «структура кредита, стадии движения кре- 
дита и основа кредита» [Деньги, кредит, банки, 2010, с. 238].

Иного мнения придерживаются М.В. Романовский и Н.И. Парусимова. Так, М.В. Романовский считает, что «постоянным проявлением сущности кредита во всех формах являются перераспределительная функция и функция создания кредитных орудий обращения» [Финансы и кредит, 2003, с. 339], а Н.И. Парусимова заявляет, что «сущность кредита следует определять как возвратный обмен ссужаемой стоимости между кредитором и заемщиком, растянутый во времени и основанный на доверии» [Парусимова, 2002, с. 50]. Обобщая сказанное, можно предположить, что определения сущности кредита слабо согласуются.

Помимо сущности кредита, важным аспектом в теории кредита является его природа, трактуемая как врожденные свойства, естественное состояние, принадлежность кредита к определенному роду. Так, по мнению О.И. Лаврушина [Деньги, кредит, банки, 2010, с. 237] и М.В. Романовского [Финансы и кредит, 2003, с. 325], кредит принадлежит к роду стоимости. И.В. Топровер иного мнения, он считает, что кредит соотносится с «семейством» экономических обязательств, «К важнейшим атрибутам которого следует отнести доверие, время, особенности отношений присвоения, взаимность со всеми стадиями общественного воспроизводства» [Топровер, 2006, с. 15]. В противоположность его мнению О.И. Лаврушин [Деньги, кредит, банки, 2010 , с. 246,247$]$ к фундаментальным качествам кредита относит возвратность, платность, срочность и сохранение стоимости. Однако, по мысли Н.И. Парусимовой [Парусимова, 2002, с. 50], свойство сохранения сто- имости - это родовое качество денег, а не кредита. Таким образом, природу кредита исследователи трактуют по-разному, что подтверждает вывод об отсутствии согласованности и единства во взглядах ученых.

Вместе с тем можно согласиться с мнением М.А. Песселя [Пессель, 1977, с. 54], В.В. Кочкарева [Кочкарев, 1980, с. 59], О.И. Лаврушина [Деньги, кредит, банки, 2010, с. 237], М.В. Романовского [Финансы и кредит, 2003, с. 324], В.И. Букато [Букато и др., 2001, c. 252], что кредит это экономическая категория, которая рассматривается как один из видов общественных отношений, отражающих экономические связи, взаимосвязи и взаимодействия объекта.

Так, Е.Ф. Жуков [Деньги ..., 2003, с. 170, 207] и Г.М. Колпакова [Колпакова, 2000, с. 341] считают, что кредит - это движения ссудного капитала. В Финансово-кредитном энциклопедическом словаре $[2004$, с. 440$]$ и в Экономической энциклопедии Л.И. Абалкина [1999, с. 338] кредит отражает разновидность экономической сделки, принимающей форму ссуды, когда один партнер предоставляет другому деньги или имущество на условиях срочности, возвратности и, как правило, платности. В Оксфордском толковом словаре [Финансы ..., 1997 , c. 102] кредит - сумма денег, на которую коммерсант позволяет своему клиенту приобрести товар, не требуя немедленной оплаты.

Анализ литературы в этом аспекте показал, что определений кредита много (см. таблицу), каждое из которых выражает нечто специфическое в кредите, либо одно или несколько качеств кредита, либо состав участников кредитной сделки, либо показывает ту или иную его особенность, структуру, основу, движение.

Таблиияа

Определения категории «кредит»

\begin{tabular}{|l|l|}
\hline \multicolumn{1}{|c|}{ Определение } & \multicolumn{1}{|c|}{ Аспекты объекта } \\
\hline «Кредит (лат. Credit - «он верит») - разновидность экономиче- & Кредит - это вид сделки. \\
ской сделки, принимающая форму ссуды, когда один партнер & Кредит - это ссуда. \\
предоставляет другому деньги или имущество на условиях \\
срочности, возвратности и, как правило, платности» [Эконо- \\
мическая энциклопедия, 1999, с. 338] & $\begin{array}{l}\text { Условия кредита - деньги или имущество. } \\
\text { платность }\end{array}$ \\
\hline $\begin{array}{l}\text { «Кедит (от лат. Сredit - «он верит») - разновидность экономи- } \\
\text { ческой сделки, принимающая форму ссуды, когда один партнер }\end{array}$ & Кредит - это вид сделки. \\
предоставляет другому деньги или имущество на условиях сроч- & $\begin{array}{l}\text { Предмет кредита - деньги или имущество. } \\
\text { ности, возвратности и, как правило, платности» [Большая эконо- } \\
\text { мическая энциклопедия, 2008, с. 315] }\end{array}$ \\
\hline
\end{tabular}

Примечание. Составлено автором. 
Таблица (Окончание)

\begin{tabular}{|c|c|}
\hline Определение & Аспекты объекта \\
\hline $\begin{array}{l}\text { «Кредит (от лат. Creditum - нечто, переданное другому с уве- } \\
\text { ренностью в возврате; англ. credit) - экономическая сделка, } \\
\text { при которой один партнер предоставляет другому денежные } \\
\text { средства или имущество на условиях срочности, возвратности } \\
\text { и платности. Кредит - главная функция (услуга) кредитного } \\
\text { учреждения (кредитора)» [Финансово-кредитный энциклопе- } \\
\text { дический словарь, 2004, с. 440] }\end{array}$ & $\begin{array}{l}\text { Кредит - это сделка. } \\
\text { Кредит - функция кредитора. Предмет кре- } \\
\text { дита - деньги или имущество. } \\
\text { Условия кредита - возвратность, срочность, } \\
\text { платность }\end{array}$ \\
\hline $\begin{array}{l}\text { «Сredit (кредит; доверие): 1. Репутация и финансовое положе- } \\
\text { ние частного лица или организации. 2. Сумма денег, на кото- } \\
\text { рую коммерсант позволяет своему клиенту приобрести товар, } \\
\text { не требуя немедленной оплаты. 3. Способность граждан при- } \\
\text { обретать товары на деньги, занятые у финансовых компаний, } \\
\text { банков и других денежных кредиторов» [Финансы ..., } 1997 \text {, } \\
\text { с. } 102]\end{array}$ & $\begin{array}{l}\text { Кредит - это репутация, способность. } \\
\text { Предмет кредита - деньги. } \\
\text { Условие кредита - отсроченность }\end{array}$ \\
\hline $\begin{array}{l}\text { «Кредит - форма движения ссудного капитала. Ссудный капи- } \\
\text { тал - это денежный капитал, представляемый в ссуду на усло- } \\
\text { виях срочности, возвратности, платности и обеспеченности } \\
{[\text { Колпакова, 2000, с. } 341]}\end{array}$ & $\begin{array}{l}\text { Кредит - форма движения ссудного капитала. } \\
\text { Предмет кредита - денежный капитал. } \\
\text { Кредит - это ссуда. } \\
\text { Условия кредита - возвратность, срочность, } \\
\text { платность и обеспеченность }\end{array}$ \\
\hline $\begin{array}{l}\text { «Кредит - это экономические отношения в связи с движением } \\
\text { стоимости на условиях возвратности к исходному пункту } \\
\text { (кредитору)» [Букато и др., 2001, с. 252] }\end{array}$ & $\begin{array}{l}\text { Кредит - это экономические отношения. } \\
\text { Предмет кредита - стоимость. } \\
\text { Условие кредита - возвратность } \\
\end{array}$ \\
\hline $\begin{array}{l}\text { «Кедит - это экономическая категория, в условиях товарного } \\
\text { производства выражает производственные отношения, кото- } \\
\text { рые возникают в социалистическом обществе, выступает од- } \\
\text { ним из важнейших средств дальнейшего развития производи- } \\
\text { тельных сил страны, подъема экономики, культуры, жизнен- } \\
\text { ного уровня трудящихся» [Кочкарев, 1980, с. 59] }\end{array}$ & $\begin{array}{l}\text { Кредит - это экономическая категория. } \\
\text { Кредит - это производственные отношения. } \\
\text { Кредит - это средство развит ия }\end{array}$ \\
\hline $\begin{array}{l}\text { «Кредит - не всякое общественное отношение, а лишь такое, } \\
\text { которое отражает экономические связи, движение стоимости» } \\
\text { [Деньги, кредит, банки, 2010, с. 237] }\end{array}$ & $\begin{array}{l}\text { Кредит - это экономические отношения. } \\
\text { Предмет кредита - стоимость }\end{array}$ \\
\hline $\begin{array}{l}\text { «Кредит - экономическая категория, присущая социалистиче- } \\
\text { скому хозяйству, и в ней находят выражение производствен- } \\
\text { ные отношения, возникающие в тех случаях, когда социали- } \\
\text { стическое государство, хозяйственные организации или от- } \\
\text { дельные лица передают друг другу стоимость на условиях воз- } \\
\text { вратности во временное пользование» [Пессель, } 1977, \text { с. } 54]\end{array}$ & $\begin{array}{l}\text { Кредит - это экономическая категория. } \\
\text { Кредит - это производственные отношения. } \\
\text { Предмет кредита - стоимость. } \\
\text { Условие кредита - возврат ность, срочность }\end{array}$ \\
\hline $\begin{array}{l}\text { «Кредит - движение ссудного капитала. Ссудный капитал - } \\
\text { это денежный капитал, отдаваемый капиталистами - } \\
\text { собственниками в ссуду, обслуживающий в основном круго- } \\
\text { оборот функционирующего капитала и приносящий проценты } \\
\text { на основе эксплуатации наемного труда» [Деньги ... , 2003, } \\
\text { с. } 170] . \\
\text { «Ссудой денег для заемщика служит всякий кредит, обеспе- } \\
\text { ченный реальным залогом, ссудой капитала - кредит, не обес- } \\
\text { печенный залогом» [Деньги ..., 2003, с. 207] }\end{array}$ & $\begin{array}{l}\text { Кредит - движение ссудного капитала. } \\
\text { Предмет кредита - денежный капитал. } \\
\text { Кредит - это ссуда. } \\
\text { Условия кредита - платность и обеспечен- } \\
\text { ность }\end{array}$ \\
\hline $\begin{array}{l}\text { «Кредит - это экономическая категория, представляющая со- } \\
\text { бой определенный вид общественных отношений, связанных с } \\
\text { движением стоимости на условиях возвратности» [Финансы и } \\
\text { кредит, } 2003, \text { с. } 324]\end{array}$ & $\begin{array}{l}\text { Кредит - это экономическая категория. } \\
\text { Предмет кредита - стоимость. } \\
\text { Условия кредита - возвратность }\end{array}$ \\
\hline
\end{tabular}

Приведенные определения кредита хотя и не являются исчерпывающими, но в совокупности дают представление о сложившихся к настоящему времени подходах к определению искомой категории. Определения дефиниции «кредит» позволяют выявить наиболее распро- страненные элементы и те, которые встречаются редко. Часто кредит рассматривают как экономическую категорию, экономические отношения, движение ссудного капитала, вид сделки, форму ссуды, редко - как функцию, средство, репутацию и способность. 
Обращают на себя внимание в имеющихся определениях кредита такие важные аспекты, как предмет и условия кредита. Чаще всего исследователи указывают на то, что в качестве кредита предоставляют деньги или имущество, реже - только деньги. В качестве условий чаще всего называют срочность, платность и возвратность, реже комбинации из них, дополненные обеспеченностью.

Кредит - экономическая категория, которая в силу разных причин связана с такими категориями, как «ссуда», «депозит», «вексель», «облигация», «лизинг», «факторинг», «займ».

В экономической литературе достаточно часто «кредит», «ссуда» и «депозит» рассматриваются как синонимы, но если обратиться к характеристике кредитных операций в монографии коллектива авторов «Банковская система России: настольная книга банкира», то становится понятно, что депозит и ссуда - разновидности кредита, так как «кредитные операции включают в себя ссудные и депозитные операции» [Банковская система России, 1995, с. 58].

Помимо этого, в Большой экономической энциклопедии кредит определен как «разновидность экономической сделки, принимающей форму ссуды» [Большая экономическая энциклопедия, 2008, с. 315]. Депозит - это форма выражения кредитных отношений, вид хранения ценностей. Облигация, с одной стороны, это долгосрочная эмиссионная ценная бумага, а с другой - долгосрочная форма займа. Всем известно, что вексель - орудие коммерческого кредита, краткосрочный кредит можно оформить, используя вексель. Итак, с одной стороны, вексель - это форма коммерческого кредита, а с другой стороны ценная бумага.

«Лизинг» буквально в переводе с английского означает аренду вещей. По существу, лизинг, с одной стороны, - это аренда вещей, а с другой - долгосрочная форма кредитования основных средств. Факторинг - это финансирование под уступку денежного требование, с одной стороны, с другой - это особая краткосрочная форма кредитования. Займ и кредит довольно часто используют как синонимы. О.И. Лаврушин считает, что кредит и займ - родовые понятия с одними и теми же свойствами [Деньги, кредит, банки, 2010, c. 236]. Возможно, свойства этих понятий одни и те же, но качество свойств - разное. Так, займ может быть платным и бесплатным, срочным и бессрочным, возвратным и даровым, оформлен ценной бумагой или договором, а кредит оформляется договором, в котором фиксируются срок, порядок возврата и уплаты процентов за кредит.

В итоге анализ литературы показал, что в существующих определениях категории «кредит» нет полноты, согласованности и системности, проблема адекватного отображения сущности и природы кредита остается неразрешенной.

\section{Теория и методология исследования}

Целью исследования является разработка дефиниции категории «кредит», отражающая природу, сущность, суть именуемого ею феномена.

В число основных элементов, а точнее основных свойств кредита, с помощью которых определяется дефиниция «кредит», входят такие понятия, как «возвратность», «платность» и «срочность». Следует признать, что «возвратность кредита вне зависимости от стадий движения ссужаемой стоимости является всеобщим свойством кредита» [Деньги, кредит, банки, 2010, с. 247]. Не вызывает сомнения и факт того, что возвратность - объективное свойство кредита, означающее возвратное движение денежных и неденежных ресурсов, переданных во временное пользование субъекту кредита, удовлетворив потребности которого они возвращаются к кредитору.

Платность - необходимое условие существования современных кредитных отношений. Кредит не может существовать без оплаты, так как если нет оплаты, то нет и стимула вступать в кредитные отношения. Платность кредита является его свойством. Платный характер не только порождает движение кредитных ресурсов, но и отражает доверие кредитора к заемщику.

Срочность есть не что иное, как временная определенность возвратности кредита. Срочность кредита дополняет (уточняет) объективное свойство кредита, в равной сте- 
пени выступает свойством кредита, свидетельствующем о том, что кредит должен быть не просто возвращен, а возвращен в строго определенный договором срок.

Научное исследование сути, сущности и природы феномена «кредит» проводится в три этапа. На первом этапе с помощью формально-логического метода сформулируем определение дефиниции «кредит», на втором этапе на основе формальной логики и с применением метода триадической дешифровки категорий получим развернутое научно обоснованное определение категории «кредит». На заключительном этапе будет подготовлен вывод, в котором результаты исследования предстанут в систематизированном и обобщенном виде.

Современной экономической науке известно множество методологических подходов: системный, эволюционный, исторический, институциональный, воспроизводственный, функциональный, процессный, категориальный, диалектический, субъектный. Все подходы продуктивны, но не все методы названных подходов применимы для решения задач конструирования дефиниции категории «кредит».

Для достижения цели исследования конструирования дефиниции категории «кредит» нами использовался формально-логический метод определения понятия и метод триадической дешифровки категорий из категориально-системной методологии, описанные в источнике: [Разумов, 2004, с. 36, 78]. Категориально-системная методология позволяет добывать новые знания «об исследуемых объектах на ранних стадиях исследования и в наиболее сложных и запутанных, противоречивых когнитивных ситуациях» [Разумов, 2004, с. 15].

Формально-логический метод предложен В.А. Светловым [Светлов, 2013, с. 39] в пособии «Практическая логика». Этот продуктивный метод конструирования дефиниций позволяет сконструировать представление о любом объекте исследования, если есть возможность выделения условий отнесения объектов к классу и дополнению и возможность применения идеи триадичности к конструированию определения понятия. С помощью этого метода можно логически корректно ввести в предметное поле собственные определения.
Логика метода следующая:

1) мысленно сравниваем объект исследования, понятие о котором необходимо сконструировать, с другими понятиями подобного рода и определяем множество необходимых условий;

2) то условие, которое подчиняет все остальные, будет родовым, а все остальные видовыми; находим соответствующий родовому понятию универсум;

3) проверяем необходимое условие на достаточность; если необходимое условие не является достаточным, то проверяем следующее условие из множества необходимых условий;

4) формулируем определение искомой дефиниции.

Метод исследования, основанный на идеи триадичности, позволяет в гносеологически емком виде описать любой объект, считает В.И. Разумов [Разумов, 2004, с. 36, 78]. Его используют исследователи разных отраслей наук для определения сущности и природы своего объекта исследования, но не часто. Триада - это система категорий из трех единиц, с помощью которой можно описать любой объект исследования. Одноуровневая триадическая дешифровка категории позволяет выявить наиболее существенные качества в объекте исследования, составляющие в совокупности его сущность, суть, природу, смысл [Разумов, 2004, с. 37], при условии, если есть возможность описать отдельные аспекты исследуемого объекта, связанные между собой какими-либо отношениями, и возможность дешифровки аспектов объекта исследования на втором уровне.

Логика метода исследования следующая:

1) выбираем ключевую категорию для работы с ней как объектом исследования;

2) логически подбираем аспекты объекта, в качестве которых могут выступать категории и понятия, описывающие объект исследования; дешифруем понятие на первом уровне;

3) далее распределяем категории и понятия по вершинам триады с учетом осмысленных связей между соседними категориями и понятиями; дешифруем понятие на втором уровне; 
4) формулируем развернутое определение искомой дефиниции.

Продуктивность этого метода позволяет построить модели объекта в формате динамической информационной системы.

\section{Результаты исследования}

Конструирование краткой дефиниции категории «кредит» формально-логическим методом.

Мысленно сравниваем экономическую категорию «кредит» с другими категориями, такими как «займ», «депозит», «ссуда», «лизинг», «факторинг», «облигация», «вексель», фиксируем в качестве необходимых условий:

1) передать или получить ценности в денежной или неденежной форме взаймы;

2) вернуть (возместить) займ того же рода и качества;

3) вернуть займ и оплатить процент в определенный срок.

Первое из них является родовым. Следовательно, универсум состоит из класса займов. Условие - «возвратность (возмездность) займа того же рода и качества» разбивает универсум на класс «возвратный (возмездный) займ того же рода и качества» и дополнение к классу «невозвратный (безвозмездный) займ того же рода и качества». Первое условие включает в класс «кредит» категории «депозит», «ссуда». Следовательно, не все займы относятся к классу «кредит». Поэтому требуется дальнейшее разбиение универсума с помощью условия «вернуть займ и оплатить процент в определенный срок», которое отделяет ссуду от депозита. Депозит может быть бесплатным, ссуда - нет. Схема определения дефиниции «кредит» представлена на рисунке 1.

Дефиниции категории «кредит» следующие: 1) кредит - это вид возвратных, платных и срочных займов денег и товаров; 2) кредит это определенный возвратностью, срочностью и платностью вид займов денег и товаров.

Конструирование развернутой дефиниции категории «кредит» методом триадической дешифровки.

Экономическая категория «кредит» отличается от некредитных видов займа возвратностью, платностью и срочностью. Используем эти сущностные характеристики для дешифровки понятия «кредит» на первом уровне.

1. Возвратность. Главный аспект кредита, отвечает на вопрос: «Что возвращать?» Возврату подлежат денежные и неденежные ценности того же рода и качества, качество которых во многом зависит от источника возврата кредита.

2. Платность. Важный, фундаментальный аспект кредита, отвечает на два вопроса: «За что платить?» и «Как платить?» Уплатить заемщик должен ссудный процент за пользование денежными и неденежными ценностями, причем определенным способом.

3. Срочность. Определяющий аспект кредита, отвечает на вопрос: «Какой срок кредита?» Срок кредита зависит от возможностей кредитора и способностей заемщика.

Шифруем триаду «кредит»: [0] возвратность, [1] платность, [2] срочность. На рисунке 2 представлен первый этап конструирования понятия дефиниции «кредит» методом триад.

Далее с целью формирования второго уровня дешифровки определяем еще один комплекс категорий и понятий, обеспечивающий дешифровку категорий первого уровня.

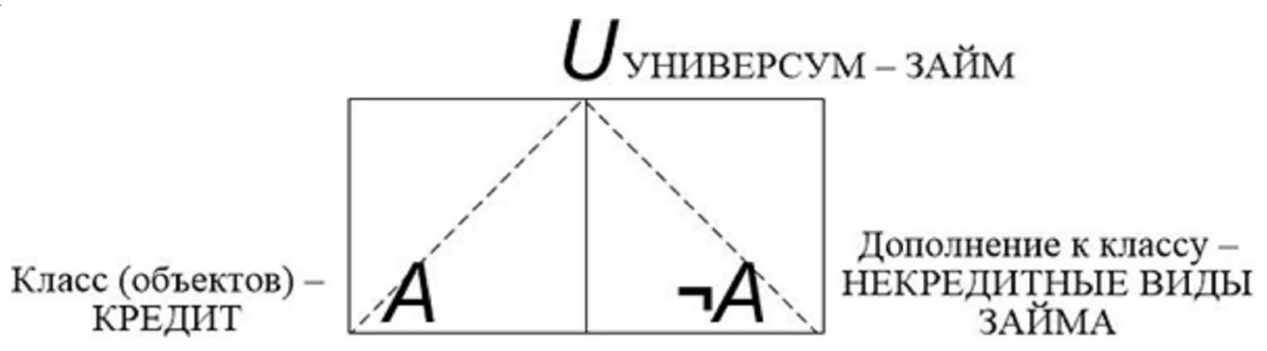

Рис. 1. Модель дефиниции категории «кредит»

Примечание. Составлено автором. 
Важным аспектом возвратности кредита является источник возврата. В качестве источника возврата кредита могут выступать выручка (доход), прибыль (накопления) заемщика, залог, поручительство и гарантии третьих лиц, страхование. Все источники сгруппированы в группы предпочтительности кредитора: основные источники возврата полученных во временное пользование кредитных средств: выручка (доход), прибыль (накопления) заемщика; дополнительные источники возврата кредита, для использования которых в качестве источника возврата кредита необходимо приложить определенные усилия, это залог, поручительство, гарантия; недостаток или отсутствие основных и/ или дополнительных источников возврата кредита предполагает использование страхования кредита. Таким образом, аспект кре- дита «возвратность» дешифруется понятиями: [00] основные источники; [01] основные и дополнительные источники; [02] основные источники и страхование.

Платность как фундаментальный аспект кредита дешифруется по способу (технологии) уплаты ссудного процента. В современной практике кредитования используются способы предоплаты, постоплаты и равномерной оплаты. Дешифровка платности следующая: [10] предоплата; [11] равномерная оплата; [12] постоплата.

Срочность как определяющий аспект кредита вполне очевидно дешифруется исходя из срока, на который выдается кредит: [20] краткосрочный, [21] среднесрочный и [22] долгосрочный.

Результат двухуровневой дешифровки категории «кредит» представлен на рисунке 3.

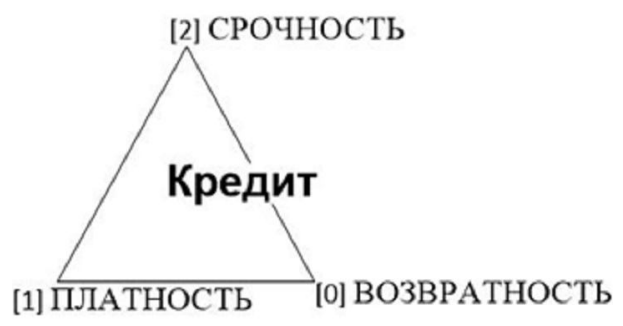

Рис. 2. Модель базовых аспектов категории «кредит»

Примечание. Составлено автором.

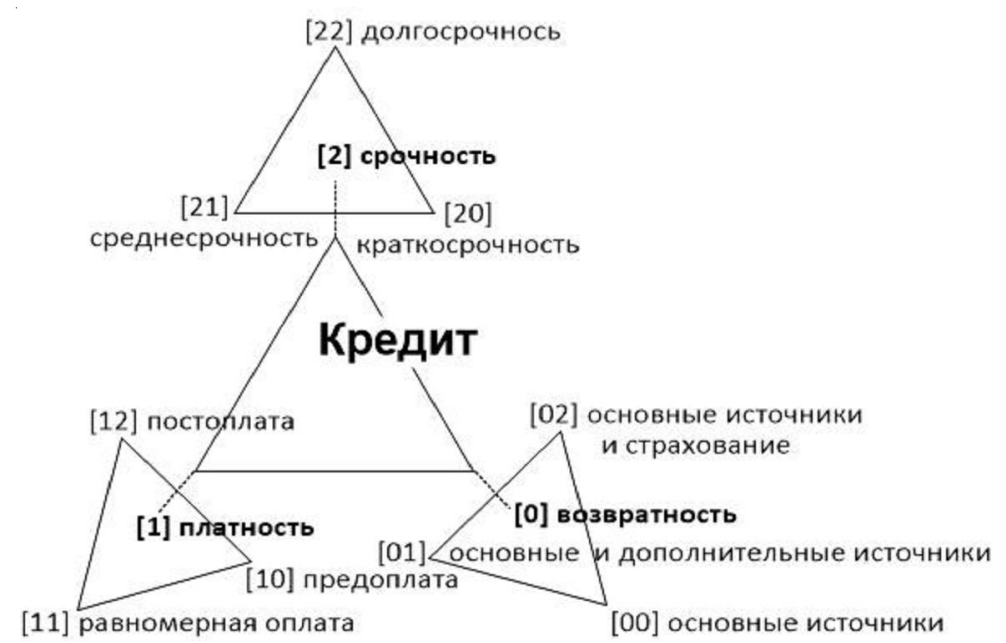

Рис. 3. Развернутая модель категории «кредит»

Примечание. Составлено автором. 
Использование метода двухуровневой триадической дешифровки позволило получить следующее развернутое определение дефиниции «кредит»: кредит - это вид займа денег и товаров, обладающий свойствами возвратности за счет основных, дополнительных источников возврата кредита и страхования; платности на условиях предварительной, равномерной и последующей уплаты ссудного процента; исходя из кратко-, средне- и долгосрочной срочности.

Кредит - это кратко-, средне- и долгосрочный вид займа денег и товаров, обладающий свойствами возвратности и платности за счет основных, дополнительных источников возврата и страхования на условиях предварительной, равномерной и последующей уплаты ссудного процента и основного долга.

\section{Выводы и заключение}

Результаты настоящего исследования вносят вклад в развитие теории кредита, в частности - в решение проблемы адекватного отображения природы, сущности и сути кредита. В исследовании формулируются промежуточные выводы относительно продуктивности методов формальной логики и идеи триадичности системно-категориальной методологии для исследования природы объекта и проверки полученного определения объекта на предмет логической корректности. Проведенное исследование позволило: 1) сделать вывод о том, что среди существующих определений кредита нет полноты, согласованности и системности; 2) получить научно обоснованное простое и развернутое определение дефиниции «кредит».

\section{СПИСОК ЛИТЕРАТУРЫ}

Банковская система России : [настольная книга банкира] / Г. С. Панова [и др.]. - М. : ДеКа, 1995.$688 \mathrm{c}$.

Большая экономическая энциклопедия : БЭЭ : самое полное современное издание: более 7000 экономических терминов и понятий / Т. П. Варламова [и др.] ; отв. ред. Н. В. Дубенюк. -М. : Эксмо, 2008. -816 с.
Большой экономический словарь / авт.-сост. А. В. Борисов. - М. : Кн. мир, 2000. -895 с.

Букато, В. М. Банки и банковские операции в России / В. М. Букато, В. Ю. Головин, Ю. И. Львов. - 2-е изд., перераб. и доп. / под. ред. М. Х. Лапидуса. - М. : Финансы и статистика. 2001. $-368 \mathrm{c}$.

Деньги, кредит, банки : учеб. для студентов вузов / О. И. Лаврушин [и др.] ; под ред. О. И. Лаврушина. - 9-е изд., стер. - М. : КноРус, 2010. $559 \mathrm{c}$.

Деньги. Кредит. Банки : учеб. для студентов вузов, обуч. по экон. спец. / Е. Ф. Жуков [и др.]; под ред. Е. В. Жукова. - М. : Банки и биржи : ЮНИТИ, 2003. -623 c.

Колпакова, Г. М. Финансы. Денежное обращение. Кредит : учеб. пособие / Г. М. Колпакова. - М. : Финансы и статистика, 2000. $366 \mathrm{c}$.

Кочкарев, В. В. Кредитные отношения Госбанка с межхозяйственными организациями : монография / В. В. Кочкарев. - М. : Финансы, 1980. $-159 \mathrm{c}$.

Парусимова, Н. И. Методологические аспекты анализа кредитного дела современной России / Н. И. Парусимова // Вестник ОГУ. - 2002. № 4. - С. 50-56.

Пессель, М. А. Финансово-кредитный механизм интенсификации общественного производства / М. А. Пессель. - М. : Финансы, 1977. $224 \mathrm{c}$.

Разумов, В. И. Категориально-системная методология в подготовке ученых : учеб. пособие / В. И. Разумов, вступ. ст. А. Г. Теслинова. Омск : ОмГУ, 2004. -277 с.

Светлов, В. А. Практическая логика / В. А. Светлов. - М. : Lennex Corp : Нобель Пресс, 2013. $624 \mathrm{c}$.

Топровер, И. В. О природе и свойствах кредита: атрибуты кредитного отношения / И. В. Топровер // Финансы и кредит. - 2006. - № 28 (323). C. $15-27$.

Финансово-кредитный энциклопедический словарь / под общ. ред. А. Г. Грязновой. - М. : Финансы и статистика, 2004. -1165 с.

Финансы : Оксфорд. толковый слов. : Англо-русский / Б. Батлер [и др.]. - М. : Весь Мир, 1997. $496 \mathrm{c}$.

Финансы и кредит : учеб. для студентов вузов / М. В. Романовский [и др.] ; под ред. М. В. Романовского, Г. Н. Белоглазовой. - М. : Юрайт, 2003. $-575 \mathrm{c}$.

Экономическая энциклопедия / науч.-ред. совет издва «Экономика»; Ин-т экономики РАН ; гл. ред. Л. И. Абалкин [и др.]. - М. : Экономика, 1999. -1055 с. 


\section{REFERENCES}

Panova G.S., Gryaznova A.G., Lavrushin O.I., Molchanov A.V., Tavasiev A.M. et al. Bankovskaya sistema Rossii: [nastolnaya kniga bankira] [Banking System of Russia. (Banker's Desk Book)]. Moscow, DeKa Publ., $1995.688 \mathrm{p}$.

Varlamova T.P. et al. Bolshaya ekonomicheskaya entsiklopediya: BEE: samoe polnoe sovremennoe izdanie: bolee 7000 ekonomicheskikh terminov $i$ ponyatiy [Big Economic Encyclopedia: The Most Complete Modern Edition: More Than 7,000 Economic Terms and Concepts]. Moscow, Eksmo Publ., 2008. 816p.

Borisov A.B. Bolshoy ekonomicheskiy slovar [Great Economic Dictionary]. Moscow, Knizhnyy mir Publ., 2000. 895 p.

Bukato V.M., Golovin V.Yu., Lvov Yu.I. Banki $i$ bankovskie operatsii $v$ Rossii [Banks and Banking Operations in Russia]. Moscow, Finansy i statistika Publ., 2001.368 p.

Lavrushin O.I. Dengi, kredit, banki: ucheb. dlya studentov vuzov [Money, Credit, Banks. Textbook for University Students]. Moscow, KnoRus Publ., 2010. 559 p.

Zhukov E.F., Maksimova L.M., Pechnikova A.V. et al. Dengi. Kredit. Banki: ucheb. dlya studentov vuzov, obuch. po ekon. spets. [Money. Credit. Banks. Textbook for University Students of Economic Specialties]. Moscow, Banki i birzhi Publ., YuNITI Publ., 2003. 623 p.

Kolpakova G.M. Finansy. Denezhnoe obrashchenie. Kredit: ucheb. posobie [Finance. Money Turnover. Credit. Study Guide]. Moscow, Finansy i statistika Publ., 2000. 366 p.

Kochkarev V.V. Kreditnye otnosheniya Gosbanka s mezhkhozyaystvennymi organizatsiyami: monografiya [Credit Relations of the State Bank
With Inter-Economic Organizations: Monograph]. Moscow, Finansy Publ., 1980. 159 p.

Parusimova N.I. Metodologicheskie aspekty analiza kreditnogo dela sovremennoy Rossii [Methodological Aspects of the Analysis of Credit Business in Modern Russia]. Vestnik $O G U$ [OSU Bulletin], 2002, no. 4, pp. 50-56.

Pessel M.A. Finansovo-kreditnyy mekhanizm intensifikatsii obshchestvennogo proizvodstva [Financial and Credit Mechanism for Intensification of Public Production]. Moscow, Finansy Publ., 1977. 224 p.

Razumov V.I. Kategorialno-sistemnaya metodologiya $v$ podgotovke uchenykh: ucheb. posobie [Categorical-Systematic Methodology in the Training of Scientists. Study Guide]. Omsk, OmGU, 2004. 277p.

Svetlov V.A. Prakticheskaya logika [Practical Logic]. Moscow, Lennex Corp, Nobel Press, 2013. 624 p.

Toprover I.V. O prirode i svoystvakh kredita: atributy kreditnogo otnosheniya [On the Nature and Properties of Credit: Attributes of a Credit Relationship]. Finansy $i$ kredit [Finance and Credit], 2006, no. 28 (323), pp. 15-27.

Gryaznova A.G., ed. Finansovo-kreditnyy entsiklopedicheskiy slovar [Financial and Credit Encyclopedic Dictionary]. Moscow, Finansy i statistika Publ., 2004. 1165 p.

Butler B. et al. Finansy: Oksford. tolkovyy slov: Anglo-russkiy [Finance: Oxford Interpretive Dictionary: English-Russian]. Moscow, Ves Mir Publ., 1997. 496 p.

Romanovsky M.V., Nazarov N.N., Popova M.I. Finansy $i$ kredit: ucheb. dlya studentov vuzov [Finance and Credit. Study Guide for Universities]. Moscow, Yurayt Publ., 2003. 575 p.

Abalkin L.I. et al., eds. Ekonomicheskaya entsiklopediya [Economic Encyclopedia]. Moscow, Ekonomika Publ., 1999. 1055 p.

\section{Information About the Author}

Elena G. Revtova, Candidate of Sciences (Economics), Associate Professor, Department of Banking and Insurance, Orenburg State University, Prosp. Pobedy, 13, 460000 Orenburg, Russian Federation, revtovaelena70@mail.ru, https://orcid.org/0000-0002-7020-1284

\section{Информация об авторе}

Елена Геннадьевна Ревтова, кандидат экономических наук, доцент кафедры банковского дела и страхования, Оренбургский государственный университет, просп. Победы, 13, 460000 г. Оренбург, Российская Федерация, revtovaelena70@mail.ru, https://orcid.org/0000-0002-7020-1284 